\title{
Surgical and Safety Considerations of Multichannel Cochlear Implants in Children
}

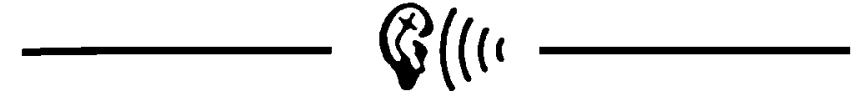

Graeme M. Clark, FRACS; Noel L. Cohen, MD; Robert K. Shepherd, PhD

Department of Otolaryngology, Royal Victoria Eye and Ear Hospital, Melbourne, Australia (G.M.C.; R.K.S.) and Department of Otolaryngology, New York University Medical Center, New York (N.L.C.)

MULTIPLE-CHANNEL COCHLEAR implants have become a viable surgical treatment for profoundly deaf individuals. With the Food and Drug Administration's (FDA's) June 1990 approval for the release of the 22-channel implant for children aged 2 to 17 , more hearing-impaired young people than ever before will be able to benefit from the auditory sensations provided by the device.

The surgical procedure, the complications experienced, and safety issues are somewhat different for children than they are for adults. This report describes the modifications required in the surgical procedure and discusses the complications associated with cochlear implants in children. It then addresses issues related to the safety of the device, such as the prevention of middle ear infection. Finally, it summarizes new research conducted at the University of Melbourne and supported by the National Institutes of Health concerning skull growth, explantation/reimplantation, and sealing the electrode entry point into the cochlea.

\section{SURGICAL TECHNIQUE}

The cochlear implant operation for children is performed in the conventional otologic position under general anesthesia, just as it is with adults. The procedures for maintaining asepsis are also the same. However, cochlear implant surgery in children differs in several significant ways from the operation in adults. The differences result from the relative size of the implant, the size of the child's head (especially the temporal bone), and the growth potential of the skull and mastoid process. Those factors not only require modifications of the surgical technique, but also increase the potential for both short-term and long-term complications. Moreover, the surgical techniques and potential complications vary between very young children and adolescents.
Modifications of the surgical procedure for children are discussed below, particularly with respect to flap design, the incision, drilling the well for the receiverstimulator, and routing the electrode leadwire. Otherwise, the procedures followed are the same as those described for adults in Cochlear Corporation's surgical procedure manual (Clark, Franz, Pyman, Webb, Balkany, Cohen \& Gantz, 1987). As with all implant operations, two sterile implants always should be available so that a back-up device can be used if the primary device becomes contaminated or damaged during the procedure.

\section{Flap Design}

Because the same implant is used for all ages, the relative size of the device is greater for a small child than for an adolescent or an adult. In all cases, the flap must cover the implant adequately with generous margins in all direction. Consequently, the flap will contain a larger percentage of the scalp in smaller children.

Both the inverted U-shaped flap and the anteriorly based C-shaped flap can be used in children (Webb, Pyman, Franz, \& Clark, 1990). Each design has advantages and disadvantages. The University of Melbourne uses the inverted U-shaped flap almost exclusively in both children and adults. Most North American surgeons began their adult programs using the C-shaped flap. Some of them use that flap for both children and adults, although others now use the U-shaped flap in children. In general, more surgeons currently are using the inferiorly based inverted U-shaped flap for children than the anteriorly based C-shaped one.

The inferiorly based or inverted U-shaped flap is based on the branches of the occipital and posterior auricular arteries. It can be reflected inferiorly, exposing the operative field without the use of vigorous retraction. Because venous drainage is also inferior, little edema is generally seen. The disadvantage of the $U$ shaped flap is that the proximal electrode lead crosses the anterior incision line, but it can be protected by an anteriorly based deep fascial flap.

The C-shaped flap is similar to that used in acoustic neuroma and vestibular nerve operations. It is based on branches of the posterior auricular and superficial temporal arteries and is well vascularized if properly

0196/0202/91/1204-0015S\$03.00/0 - EAR AND HEARING Copyright (C) 1991 by Williams \& Wilkins - Printed in the U.S.A. 
constructed. The incision does not cross the implant at all. The major disadvantage of the anteriorly based Cshaped flap is that it must be retracted strongly in order to expose the operative field adequately for the mastoidectomy and facial recess approach to the middle ear. Usually, that retraction does not pose a problem in small children, but may be more difficult in an older child with a thick scalp. Strong retraction may interfere with perfusion of the flap during the operation. More postoperative edema also may occur because venous drainage can only occur anteriorly, rather than with gravity. Consequently, the blood supply and postoperative healing can be affected.

\section{Incision}

In adults, the receiver-stimulator ideally should be located above a horizontal line through the outer canthus of the eye and external auditory meatus and below the supramastoid crest (temporal line) (Fig. 1). In the young skull, however, the supramastoid crest is variable in position and development. Consequently, it is not a reliable surgical landmark (G. Clark, personal observation). Furthermore, in a small child, it may be necessary to move the receiver-stimulator more cephalward than for adults in order to reach a suitably flat part of the skull. The surgeon also must take into account that a child's skull is much thinner above the supramastoid crest than below it. Therefore, the surgeon may need to expose the dura mater when drilling the well for the receiver-stimulator later in the procedure.

The position of the implant is drawn on the scalp with a marking pen. The line of the incision is then marked so that it is about $20 \mathrm{~mm}$ from the device in all directions. When a U-shaped incision is used for children (Fig. 1A), the incision has shorter anterior and posterior limbs, and a superior limb that slopes more steeply upwards than that for adults.
After the field is prepared and draped, the position of the receiver-stimulator can be marked with methylene blue. In children, a 21 -gauge needle can be dipped in methylene blue solution and inserted through the skin at the point corresponding to the center of the proposed well. The needle is rolled between the fingers so that a small amount of dye is deposited on the surface of the bone. The surgeon must execute this maneuver gently so that the needle does not penetrate the thin soft bone, or a cranial suture.

Alternatively, the site for drilling the well can be determined after the flap has been elevated and the mastoidectomy completed. In that case, the retractors must be released and the pinna repositioned so that the anterior border of the well can be placed at least 20 $\mathrm{mm}$ behind the postauricular sulcus. This positioning is important so that the external microphone can be worn comfortably without pressure on the skin overlying the device.

In making an inverted U-shaped flap, the incision goes down to the pericranium anteriorly. Superiorly, the incision goes down to the temporalis fascia. In a smaller child, surgeons may need to include the temporalis fascia or even the full thickness of the lower temporalis muscle in order to ensure a flap of adequate thickness. Posteriorly, it is important not to allow the incision to become too deep because it might cut into the nuchal muscles, with attendant bleeding.

If a C-shaped incision is used (Fig. 1B), it is important that the limbs diverge and that the superior limb lies well above the attachment of the pinna to avoid cutting the posterior branch of the superficial temporal artery. The posterior extent of the incision should be well clear of the proposed posterior margin of the receiver-stimulator.

To avoid some of the difficulties with the traditional C-shaped flap, it can be modified. The flap should have
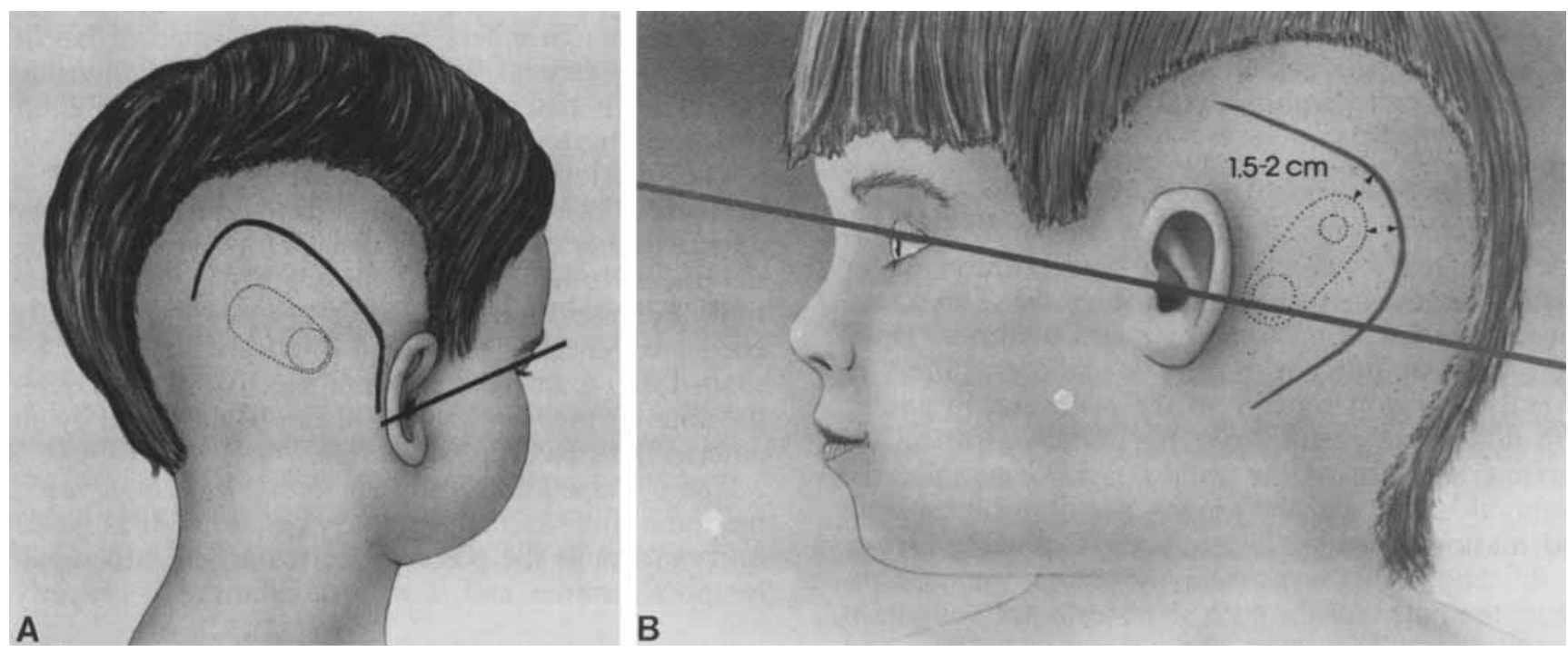

Figure 1. A) The inverted U-shaped incision and canthomeatal line in a young child (reproduced with permission from Cochlear Corporation). B) The $\mathrm{C}$-shaped incision in a young child (reproduced with permission from Cochlear Corporation). 
a more horizontal upper limb, placed higher than originally described, and a posteroinferior limb. Those modifications make the flap look more like an inverted $\mathbf{J}$ or hockey stick in shape. In making this inverted $\mathbf{J}$ shaped flap, the incision is taken down to the temporalis fascia superiorly and the deep fascia posteriorly. The tissue then is raised as a single flap.

\section{Mastoidectomy}

The mastoidectomy is performed using a standard technique. However, unlike the procedure for chronic middle ear infection, it is important not to saucerize the posterior and superior margins of the mastoid cavity. An overhang should be preserved to allow space to drill holes for tying the proximal electrode lead. It also is not necessary to perform extensive exenteration of the retro-sigmoid or tip cells because the mastoidectomy is performed only to provide access to the facial recess. The facial recess approach is discussed below.

\section{Receiver-Stimulator Well}

Drilling the well presents no particular problems in older children and the adult procedure is suitable. In smaller children, however, it is almost invariably necessary to drill down to the dura in order to achieve sufficient depth (Fig. 2). The well should be adequately deep because a shallow well not only makes an insecure anchor, but also causes the implant to protrude excessively from the side of the head. A protruding device exposes the implant to an increased risk of trauma. It also may cause thinning of the scalp and excessive magnet to magnet pressure.

If necessary, the surgeon should not hesitate to drill completely through the bone but should avoid damage

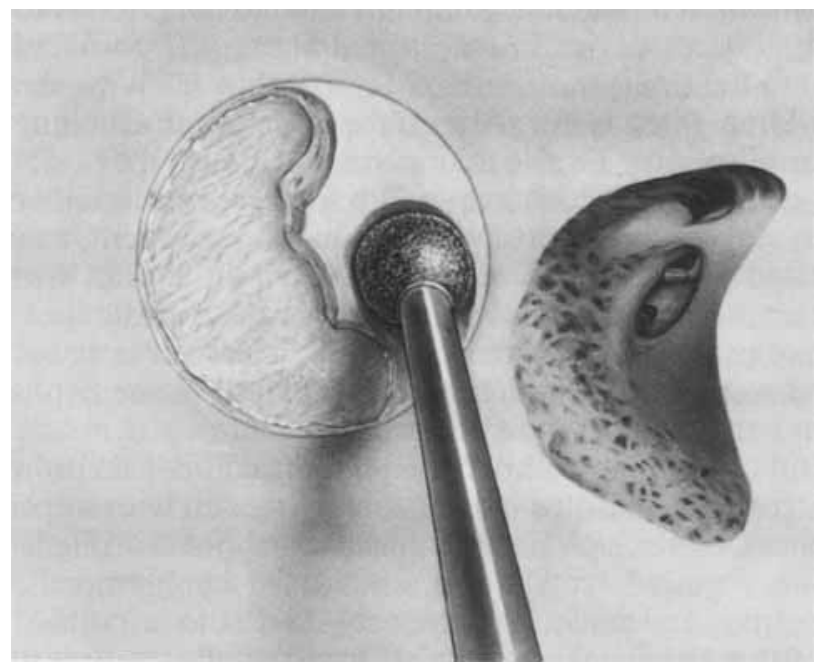

Figure 2. The cortical mastoidectomy and facial recess approach have been completed. The well for the receiver-stimulator package is being completed. The bone is being drilled down to expose dura using a diamond burr (reproduced with permission from Cochlear Corporation). to all underlying soft tissue, including the dura and the transverse sinus. A diamond burr facilitates this process.

An alternative technique is to thin the bone in the floor of the well to eggshell thickness. Then, using a small diamond burr, the surgeon can cut around the well, thereby creating a bony island. This island then can be depressed beneath the device when the receiverstimulator is secured to the skull.

After the device has been oriented and seated correctly in the well, sets of tie-down holes for the receiverstimulator package are drilled (Fig. 3). If possible, two sets are made so that ties can be placed over the anterior and posterior sections of the device. If the bone in a young child is too thin, sutures should be inserted through nearby periosteum at the conclusion of the operation. Alternatively, the anteriorly based deep fascial flap can be secured over the package to hold it in place. Holes for the ties to secure the proximal section of the lead wire are drilled either in the bone surrounding the gutter leading from the well to the mastoid cavity, or in the nearby bony overhang in the superior aspect of the mastoid cavity. We do not advise tying the implant inferiorly in children because of potential mastoid growth.

\section{Facial Recess Approach to the Middle Ear}

A facial recess approach is used to gain access to the middle ear and round window niche. An anatomical study (Bielamowicz, Cokes, Jenkins, \& Igarashi, 1988) has shown there were no significant differences between the dimensions of the facial recess in the child and adult. This suggests the facial recess approach presents no greater hazard in a child. The approach is described

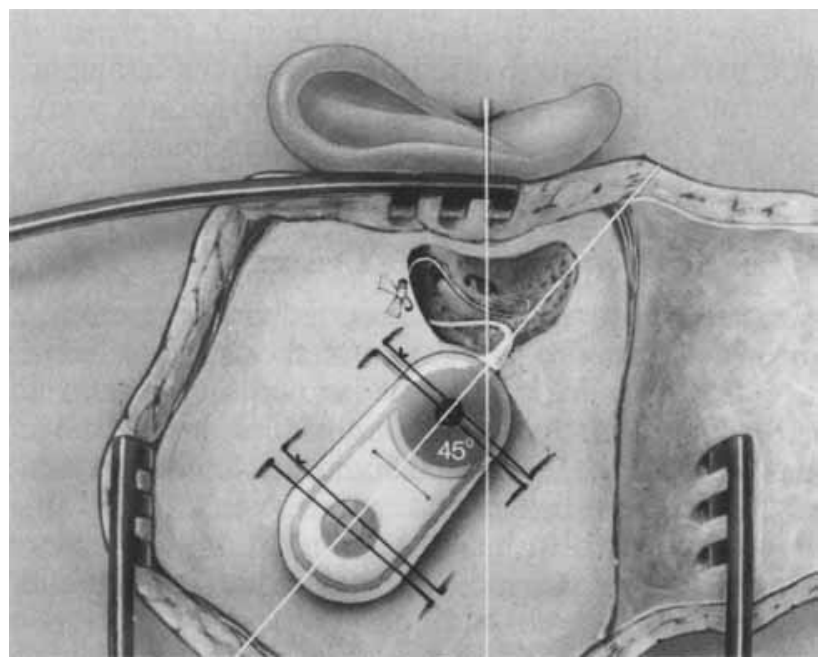

Figure 3. The well for the receiver-stimulator is joined to the cortical mastoid by a gutter, which accommodates the proximal electrode lead. Two pairs of holes are placed on either side of the well for ties to be placed over the receiver-stimulator package. A pair of holes is also drilled superiorly in the gutter or bony overhang to the mastoidectomy to receive the ties for the proximal lead wire (reproduced with permission from Cochlear Corporation). 
in detail in Clark et al (1987). Surgeons who are unfamiliar with facial recess surgery should practice the approach in a temporal bone laboratory before performing their first cochlear implant operation. During the procedure, surgeons may find that the mucosa of the middle ear may be considerably thicker and more vascular in a young child than it is in an adult. The tissue can be shrunken and the oozing controlled with local adrenaline hydrochloride.

Surgeons should remember that the round window niche is slightly posterior as well as inferior to the oval window niche. Its superior border is never more than 3 $\mathrm{mm}$ from the inferior margin of the oval window. Care must be taken not to mistake a hypotympanic air cell for the round window niche. One of the most common and devastating complications of cochlear implant surgery is to insert the electrode array into a hypotympanic cell rather than into scala tympani.

\section{Cochleostomy and Insertion of the Electrode Array}

Opening the scala tympani can be accomplished in two ways: through the bone of the promontory anteroinferior to the round window membrane or through the round window membrane. Both procedures are described in detail in Clark et al (1987) and Webb et al (1990).

Insertion of the electrode array is performed in the same way for children as for adults. This should be done gently and the electrode introduced to the point of first resistance. During insertion, the surgeon should carefully observe the electrode array at the cochleostomy. If it appears to buckle, the array should be backed off slightly, rotated, and another attempt made at insertion. When rotating the electrode, turn the array approximately $90^{\circ}$ (counter-clockwise in the right ear or clockwise in the left). It cannot be over-emphasized that a partial electrode insertion is vastly preferable to a deformed, distorted, or compressed electrode array. Once the electrode is inserted, the monopolar cautery should be turned off and disconnected.

\section{Fixation of Electrode Lead and Closure}

Once the electrode array is inserted and secured into the cochlea, the receiver-stimulator should be seated in the well. It should then be tied down securely using Dacron mesh ties looped through holes drilled above the mastoid cavity. The flap should be closed in layers, using buried resorbable sutures for the first layer. The skin is then closed with either nylon sutures or staples.

Once the incision is closed, a mastoid dressing should be applied. It should not be unnecessarily tight, especially on a small child with a thin scalp flap. Subsequently, we recommend that a single anteroposterior transorbital radiograph be taken in the operating room while the child is still under anesthesia. The radiograph ensures the correct position of the electrode array and allows the surgeon to identify improper positioning or compression of the array while still in the operating room.

\section{COMPLICATIONS}

All surgery carries with it the potential for complications. The magnitude of the risk is determined by multiple factors. Some of the factors are: the inherent danger of the operation itself, the technical skills of the surgeon, and the surgeon's experience with that particular operation or a closely related one. The placement of a large foreign body also increases the inherent risk of the surgery.

The most common complications of children's cochlear implant surgery so far have been related to the flap and the electrode placement. To date, there have been no fatal or life-threatening complications, but one facial palsy has been reported.* There have also been infrequent cases of dizziness or facial motor activity on stimulation, which were eliminated by reprogramming the speech processor. Each patient's individualized program (MAP) is stored on a programmable chip in the speech processor, which contains information on the electrodes to be stimulated and the parameters used (see Beiter, Staller, \& Dowell, Chap. 4). Several device failures have occurred, mostly spontaneously, but occasionally after head trauma. Although these are not, strictly speaking, complications of the primary surgery, they require a second operation for replacement of the implant, and therefore, the patient is once again at risk. They also emphasize that children should not play sports which require excessive body contact.

Fortunately, the rate of complication is acceptably low and compares favorably with that of the same operation in adults (Cohen, Hoffman, \& Stroschein, 1988; Webb et al, 1990; Webb, Lehnhardt, Clark, Laszig, Pyman, \& Franz, 1991).

In a series of 309 consecutive children who received the Nucleus 22-channel cochlear implant, there were 21 medical/surgical complications for an overall rate of $6.8 \%$. In a comparable group of 459 adults who received the Nucleus device in the United States, there was an overall complication rate of $12 \%$ (Table 1). With the children there were no mortalities or life-threatening complications. Twelve major complications (3.9\%), defined as those which required rehospitalization either for surgery or intravenous antibiotic treatment, occurred (Table 2): six of them involving the flap, two delayed receiver-stimulator migrations, two intraoperative perilymph "gushers," one late facial nerve palsy, and one electrode which had been placed in the hypotympanum rather than the scala tympani.

Of the six flap complications, four required revision surgery, whereas two infections were treated with intravenous antibiotics. The two receiver-stimulator migrations required reoperation, as did the hypotympanic electrode and the facial nerve palsy. It should be pointed out that the facial nerve palsy occurred after an injury

Since this analysis was performed, four additional cases of facial
palsy have been reported in a total of 548 children: one due to
operative trauma to an anomalous facial nerve and three probably
due to heat of the bone enclosing the facial nerve in the facial recess. 


\begin{tabular}{cc}
\hline Table 1. Complications in implanted adults $(N=459$ adults $)$. \\
\hline Mortality & 0 \\
Life-Threatening & 1 \\
Major & $22(5 \%)$ \\
Minor & $32(7 \%)$ \\
Total & $55(12 \%)$
\end{tabular}

Table 2. Major complications in children requiring either surgery or intravenous antibiotic treatment ( $N=309$ children).

\begin{tabular}{lc}
\hline Flap complications & 6 \\
Surgery & 4 \\
Intravenous antibiotics & 2 \\
R/S Migration & ${ }^{\theta}$ \\
Gusher & 2 \\
Facial nerve palsy & 2 \\
$\quad$ Reoperation & 1 \\
Hypotympanic electrode & 1 \\
Total & $12(3.9 \%)$ \\
\hline
\end{tabular}

${ }^{a}$ Receiver/stimulator migration.

and resulting infection and was not an operative complication. The two gushers were treated by packing the cochleostomy, with no sequelae. These were not truly surgical complications, but were the result of anatomical changes in these two children, and were handled appropriately intraoperatively. It is likely that most, if not all, complications listed in Table 2, other than the gushers and the facial nerve palsy, might have been prevented by modifications of the surgical technique used.

Minor complications, defined as those which were treated in an ambulatory setting rather than requiring admission, occurred in nine children for an incidence of $2.9 \%$ (Table 3 ). The four cases of facial nerve stimulation were either reprogrammed or resolved spontaneously. Two minor flap problems were treated with antibiotics or moleskin padding to protect the skin from excessive magnetic attraction. Two cases of postoperative dizziness resolved spontaneously, and one minor electrode migration required only reprogramming of the MAP.

Major complications occurred more frequently in the smallest children, with an incidence of $4.8 \%$ in the children under the age of $3,7.5 \%$ between the ages of 4 and 6 , and less than $2 \%$ in the children above the age of 7 (Table 4). This is a reflection of the smaller size of the young child's skull, as well as the thin nature of the scalp. These two factors contribute to the increased rate of flap problems in the younger child.

With proper flap design and intraoperative handling of the tissues, significant flap problems should be reduced almost to zero. The flap must be at least $20 \mathrm{~mm}$ from the edge of the implant in all directions. Care must be taken to elevate the flap deep to the intrinsic muscles of the scalp, down to the temporalis and deep fascia, or in the case of the small child, deep to the
Table 3. Minor medical/surgical complications in implanted children $(N=309$ children).

Facial nerve stimulation (Reprogrammed or resolved)

Flap problems $\mathrm{RX}$ antibiotic or moleskin

Dizziness (resolved)

Electrode migration (Reprogrammed)

Total 4

Table 4. Major complication occurrence by age

\begin{tabular}{cc}
\hline Age & Major Complication Rate \\
\hline $2-3$ & $4.8 \%$ \\
$4-6$ & $7.5 \%$ \\
$7-10$ & $1.8 \%$ \\
$>10$ & $1.2 \%$ \\
\hline
\end{tabular}

pericranium itself. Although an excessively thick flap may require the use of a stronger magnet and/or more powerful transmitter coil, a flap which is too thin significantly endangers the implant. It is rarely necessary to thin the flap of a child. It may be necessary when dealing with a very large adolescent, but extreme care should be taken not to thin the flap excessively. There should be no concern about having a flap which is 6 to $8 \mathrm{~mm}$ in thickness. It should also be remembered that the only area which ever needs to be thinned is that overlying the posterior part of the implant which contains both the magnet and the receiver coil.

Care must be taken in designing the flap that it has an adequate blood supply, namely, the occipital and posterior auricular arteries for the inferiorly based flap, and the superficial temporal and posterior auricular arteries for the anteriorly based flap. The two extremities of either flap should be parallel or divergent, rather than convergent. During the course of the operation, care must be taken not to allow excessive retraction of the flap or drying out. Moist gauze should be used to cover the flap during surgery.

Although the device is relatively large in the case of a small child, there should be no difficulty in closing the incision without any tension, given the ability of the scalp to slide along the surface of the skull. It is important that a mastoid dressing not be excessively tight in order to avoid compressing the flap over the implant.

Careful and thoughtful electrode placement after absolute identification of the scala tympani and the use of a radiograph in the operating room should also eliminate the devastating problem of a hypotympanic or compressed electrode array. A careful inspection of the posterior middle ear through the facial recess should reveal the round window niche and avoid confusion with a hypotympanic air cell or the so-called tunnel of the cochlea. It may be necessary to take down adhesions in order to display the anatomy more clearly, or to 
measure the distance from the oval window to what is thought to be the round window niche. This latter distance should never exceed $3 \mathrm{~mm}$. Finally, the actual electrode insertion must always be carried out with delicacy, remembering to rotate the electrode if the surgeon has the feeling of obstruction or sees buckling. Again, it is far better to have a partial insertion than a compressed electrode array.

Just as the device itself has undergone significant changes, the surgical technique is constantly evolving with the goal of reducing the complication rate still further.

\section{OTITIS MEDIA}

It is inevitable that some children who have received cochlear implants will develop serous and/or purulent otitis media subsequent to receiving their implant. There are three main concerns: that the presence of a foreign body in the middle ear will lead to an increased incidence of otitis media, that the foreign body will become contaminated and act as a nidus for infection, and that the electrode array will allow the passage of bacteria or toxins into the inner ear. In this latter case, further damage might be done to the already compromised dendrites, ganglion cells, and cochlear nerve fibers. This might negate whatever benefit the child might have received from the implant. Furthermore, it is potentially life-threatening if labyrinthitis and meningitis develop.

Fortunately, to date these theoretical concerns have proven to be largely unfounded. Experimental studies (Berkowitz, Franz, Shepherd, Clark, \& Bloom, 1987; Brennan \& Clark, 1985; Clark, Kranz, Minas, \& Nather, 1975; Clark \& Shepherd, 1984; Cranswick, Franz, Clark, Shepherd, \& Bloom, 1987; Franz, Clark, \& Bloom, 1984, 1987) have shown that tissue attachment at the electrode entry point, as well as the development of an electrode sheath, may resist the ingress of microorganisms, in particular Streptococcus pyogenes and Staphylococcus aureus, into the inner ear. The situation regarding Streptococcus pneumoniae, a common cause of otitis media in children, is still being investigated. The studies, however, also show that if otitis media occurs up to 3 weeks postimplantation, before an effective barrier has had time to form, there is a strong possibility of infection extending to the inner ear. For this reason, special care should be taken to reduce the possibility of otitis media in the early postoperative phase. The measures include postponing the operation if there is any suggestion the child is developing an upper respiratory tract infection, tympanometry the day before surgery to help exclude the possibility of a recent Eustacian tube obstruction, a high standard of aseptic surgical practice, and peri- and postoperative antibiotics. Furthermore, although the experimental studies have not shown any advantage in preventing infection from entering the inner ear by placing fibrous tissue around the electrode entry point, it is worth doing for other reasons, as it may prevent the leakage of perilymph and possibly help anchor the electrode to the region of the round window or cochleostomy.

The results of studies on experimental animals do not necessarily apply to man. It is therefore also important to note the effects of clinical trials in children. In this regard, House, Luxford, and Courtney (1985) reported neither an increased incidence nor severity of otitis media in children who had received the $3 \mathrm{M} /$ House device. Cochlear Corporation also surveyed 131 children who had received the 22-channel device, and once again, showed no increased incidence of otitis media in the implanted ear compared to the unimplanted side, and no complications from otitis media were observed.

Much work is being done on the development of alternative means of fixing the electrode to the cochlea, and it is to be hoped that these techniques will serve the additional purpose of acting as a barrier against infection. Until that time, the problem seems moot in children, because there have been no reported incidents in over 300 cases of any complications of otitis media which might be ascribed to the implant.

\section{SAFETY STUDIES}

It is a very well-accepted principle in medicine that before carrying out new surgical procedures, appropriate studies should have been undertaken humanely on experimental animals to reduce the risk to patients to a minimum. To this end, the Department of Otolaryngology at The University of Melbourne has been carrying out research to help ensure that our multiplechannel cochlear implant is safe as well as effective. Research undertaken in the department of otolaryngology was helpful in establishing that the 22-electrode implant was safe and effective for deaf adults. More recently, the department of otolaryngology has been carrying out research to ensure that the safety studies for adults were applicable to children, especially those under $2 \mathrm{yr}$ of age. More recently, the research has concentrated on the biological safety issues that are specific to young children, for example, the effects of head growth on the electrode and lead wire assembly. Our research on the safety of cochlear implantation in young children has been greatly facilitated through a contract the Department of Otolaryngology has with the National Institutes of Health to do studies on pediatric auditory prosthesis implants (contract no. NIHNo 1-NS-7-2342). ${ }^{\dagger}$

Research studies have been undertaken on temporal bone growth, methods of fixing electrodes, lead wire lengthening, effects of implantation on skull growth, the prevention of middle ear infection extending to the cochlea postimplantation, the use of safe electrical stimulus parameters, explantation and reimplantation of the electrode array, and extracochlear stimulation.

\footnotetext{
${ }^{\dagger} \mathrm{NIH}$ reports can be obtained through the office of William J. Heetderks, M.D., Neural Prosthesis Program, Room 916, Federal Building, National Institutes of Health, Bethesda, MD 20892.
} 


\section{Temporal Bone Growth}

The aim of the temporal bone growth study has been to determine how the distances between the anatomical sites that could be used to fix the electrode, lead wire assembly, or receiver-stimulator package increase over time in young children.

Measurements have been made on 30 temporal bones from an equal number of males and females whose ages have varied from 2 mo to $84 \mathrm{yr}$. The results of the anatomical studies have shown that there is a fixation point, the fossa incudis, where the distance from the round window remains the same from birth to death. This site is suitable for fixing the electrode in very young children. It also means that the electrode/ round window entry point need not be a fixation point that has to be relied upon. The study showed that fixation near Henle's point, which is currently used by many surgeons, is suitable for children over $2 \mathrm{yr}$. The mastoid tip is not as suitable in children, as it is involved in major growth change up to $6 \mathrm{yr}$. The study also showed that the change in length between the roundwindow and the site for the receiver-stimulator package bed (near sinodural angle) can be up to approximately $25 \mathrm{~mm}$. This needs to be allowed for when operating on children, especially under $2 \mathrm{yr}$, and would probably require a special lead wire assembly which would permit a length increase to occur between the fixation point and package bed without traction being applied to either end. This special lead wire assembly would not be required for children over $2 \mathrm{yr}$ of age.

\section{Fixation of the Electrode and Lead Wire}

The aim of the study on methods of fixing electrodes has been to determine how best to fix the electrode and lead wire assembly so that temporal bone growth will not result in the electrode being withdrawn from the cochlea, fractures of the electrode wires occurring, and the receiver-stimulator package being displaced.

The site for fixing the electrode lead wire in children under $2 \mathrm{yr}$ should be at a point where the distance from the round window changes little with age. As stated above, such a site is the floor of the mastoid antrum in the vicinity of the fossa incudis.

We have developed a technique for fixing the electrode array to the floor of the antrum using a platinum wire as a tie. The technique for using this tie is detailed by Webb et al (1990). It involves passing the wire around the floor of the antrum, through the facial recess, and fixing it in place before tying it around the electrode at a point protected by a Silastic sleeve. The efficacy of the tie is being studied in monkeys, where it has been used to fix the electrode lead as part of the head growth studies.

\section{Lead Wire Lengthening}

The aim of the lead wire lengthening study has been to design a lead wire assembly that would allow expansion of the lead wire to take place between two points of fixation in response to skull growth.
As our anatomical studies have shown that the distance between the round window and the package bed could increase by $25 \mathrm{~mm}$, there is a need to ensure that the intervening lead wire can straighten or expand without traction being applied to the electrode, lead wire fixation point, or receiver-stimulator package.

We have examined various lead wire expansion systems in vivo. The lead wire systems have consisted of either a helical coil or different shaped redundancies or loops. These have been implanted either as exposed lead wires or lead wires protected from fibrous tissue adhesions by a Silastic tube or bag. The systems have been implanted and attached to either the spine and inferior angle of the scapula or the spinous processes of the thoracic vertebrae in 3-mo-old kittens. Changes have been observed radiologically for periods up to 714 days. After sacrifice, the systems have been examined with a load cell for residual tension, observed macroscopically for the degree of expansion and tissue ingrowth, and studied microscopically for the nature of the tissue ingrowth.

The results are showing that a helical coil is not satisfactory as fibrous tissue ingrowth impairs its expansion. A loop may also not expand as fibrous tissue can bind it. A U-shaped redundancy appears to be the system that can most easily expand when surrounded by fibrous tissue. Results suggest that the ease of expansion of this U-shaped redundancy may be improved by encasing it in a Silastic bag, and so preventing fibrous tissue from surrounding it. Experimental studies are in progress to evaluate infection in relation to this implanted lead wire system.

In summary, our lead wire lengthening studies are showing that a U-shaped redundancy, possibly encased in a bag, is the best method of ensuring that the lead wire can expand with temporal bone growth without resulting in tension or traction on the electrode in the cochlea or fixation points. The results also suggest that the smaller degrees of temporal bone growth from $2 \mathrm{yr}$ and above only require unenclosed U-shaped redundancies between the electrode and fixation site posterior to Henle's point, and between this site and the package bed. This is current practice by implant surgeons, but needs to be stressed in a surgical manual and at training courses.

\section{Effects on Skull Growth}

The aim of the study on the effects of implantation on skull growth has been to ensure that drilling bone for the receiver-stimulator package well over cranial sutures does not affect skull growth

The Macaque monkey has been the animal model. Package beds have been drilled down to dura over the asterion (the point where the lambdoid, parieto-mastoid and occipito-mastoid sutures meet) in young monkeys. Skull growth has been monitored radiologically. Measurements have been made of skull width, height, and length and the data analyzed statistically to determine whether there is any asymmetry. The results after im- 
plantation for nearly $2 \mathrm{yr}$ show no evidence of asymmetry. These results indicate that skull asymmetry should not be a concern when carrying out implantation on very young children, and certainly not on children from $2 \mathrm{yr}$ and older. In this study we will also be examining the effects of any depression of the cortex induced by placing the receiver-stimulator in its well when drilled down to dura.

\section{Prevention of Labyrinthitis Postimplantation}

The aim of the study on the prevention of labyrinthitis postimplantation has been to determine how best to seal the opening where the electrode enters the cochlea in order to prevent an extension of a middle ear infection. This work on experimental animals follows on our previous research. The research is necessary as otitis media is frequent in young children, especially from Strep. pneumoniae.

Our results have shown that infection from Staph. aureus and Strep. pyogenes does not usually extend around the electrode entry point to produce a labyrinthitis (Brennan \& Clark, 1985). Furthermore, the results obtained using a seal from a teflon felt collar glued to the electrode were no better than those obtained without using any material to seal around the electrode entry point (Clark \& Shepherd, 1984). It is thought that fibrous tissue or bone would grow into the interstices of the teflon felt and, although not bonding with the material, would produce an effective seal by greatly increasing the microscopic path the bacteria would need to travel to gain entry to the inner ear. It was found, however, that this foreign body could, in fact, provide a niche for infection and so precipitate a chronic low grade infection. Dacron mesh produced a stronger foreign body reaction than with teflon felt and this aggravated the infection around the electrode.

It was found that infection was prevented from entering the cochlea, without any special measure to seal the electrode entry point, partly because of a fibrous tissue sheath formed around the electrode which provided a barrier against the spread of organisms (Cranswick et al, 1987). Another important finding from these studies was that if infection was present at the time of implantation or occurred 2 to 3 weeks later, before the sheath had time to form, infection was more likely to spread to the cochlea (Franz et al, 1984; Cranswick et al, 1987).

In addition to the experimental studies described above, we are also examining the effect of Strep. pneumoniae on the seal at the electrode entry point because this organism causes otitis media most frequently in young children. These experimental studies are being undertaken as part of the NIH contract "Studies on Pediatric Auditory Prostheses Implants," (No. 1-NS-72342) where we have developed a model in the cat for further investigations (Franz, Shepherd, \& Clark, 1991).

In summary, our experimental studies on cats have shown that tissue growth around the electrode entry point and a sheath that forms around the electrode in the cochlea can prevent Staph. aureus and Strep. pyogenes middle ear infections spreading into the inner ear. Infection occurring at the time of implantation or soon after, before the seal and sheath have formed, can more easily invade the cochlea. For this reason, it is important to use a clinical protocol where early infection is recognized preoperatively and infection at surgery or postoperatively is prevented. The effects of Strep. pneumonia middle ear infections postimplantation are currently being investigated in the experimental animal.

\section{Safe Electrical Stimulus Parameters}

The aim of the study on safe electrical stimulus parameters has been primarily to confirm that the stimulus parameters used by the 22-electrode multiplechannel implant for adults are safe in young animals. This applies in particular to auditory neurons and hair cells. The studies are being carried out in normal and deaf animal models.

The electrical stimulus parameters used by the Cochlear multiple-electrode implant have been shown to have no adverse effects on the cochlea or auditory neurons of adult animals (Shepherd, Clark, \& Black, 1983), and were considered safe by the FDA when it approved the device in 1985 for postlinguistically deaf individuals aged $18 \mathrm{yr}$ and above, and in 1990 for deaf children from 2 to $17 \mathrm{yr}$ of age. Nevertheless, additional studies are being undertaken to confirm that they are safe in the very young child under 2 yr of age using both normal-hearing and deaf kittens.

Young kittens have been implanted and stimulated for $8 \mathrm{hr}$ a day for 1200 to $1600 \mathrm{hr}$. Charge densities developed at the electrode surface are in the range 12 to $52 \mu \mathrm{C} \mathrm{cm}^{-2}$ geom/phase. Electrically evoked brain stem responses (EABRs) showed no evidence of either increased threshold or reduced response amplitudes with long-term stimulation. Moreover, the subsequent cochlear histology showed no evidence of hair cell or auditory nerve loss as a result of the long-term electrical stimulation. Indeed, although hair cell loss was often observed adjacent to the electrode array, hair cell survival was usually complete apical to the electrode array. Furthermore, large numbers of both inner and outer hair cells were observed adjacent to stimulating electrodes, indicating that although the insertion of the array may result in some hair cell loss locally, longterm stimulation does not contribute to additional hair cell damage.

\section{Explantation/Reimplantation of Scala Tympani Electrode Array}

The aim of the study on electrode explantation and reimplantation is to see if these procedures have any significant adverse effects on the cochlea and auditory neurons. This is necessary for children, in particular, as they would use an implant over a longer period of time than adults, and consequently there is a greater chance they will require a replacement in the years to come. 
An electrode for insertion into the cochlea should be designed so that it can be explanted and another reinserted with minimal trauma. In our own series of 107 operations it was necessary to remove the cochlear electrode and receiver-stimulator package in only one patient. This patient requested the first receiver-stimulator used in the clinical trial be replaced by the improved device as this included a magnet for the easy attachment of the head set. In addition, our first three patients, who had The University of Melbourne's prototype implanted, subsequently needed the Cochlear device. The explantation and reimplantation of arrays proved to be easy (Clark, Pyman, Webb, Franz, Redhead, \& Shepherd, 1987) especially as the prototype array was similar in design to the one developed by Nucleus Limited.

Furthermore, it was reported by Jackler, Leake, and McKerrow (1989) that in the case of 1100 patients in North and South America who had received the Cochlear device up to the end of $1988,31(2.8 \%)$ had undergone reimplantation. The reasons for replacing the device included: device failure (12), skin flap complications (10), insertion in a hypotympanic air cell or buckling of the electrode due to insertion against resistance (7), trauma with hematoma at the receiver site (1), and accidental dislodgment of the array during revision surgery to place a magnet on the standard receiverstimulator (1).

Details of the reimplantation operations were obtained in 21 out of the 31 procedures. In 20, an electrode was reinserted immediately after the other array had been removed, and the reinsertion was carried out without any difficulty. In one patient the reinsertion was performed 1 mo after explantation and, although some resistance was experienced with the reintroduction of the array, a full insertion was obtained with a good functional result.

Studies have been undertaken on cats to examine the histopathological effects of explantation and reimplantation. Research by Jackler et al (1989) has shown that a short single-ball electrode $(3 \mathrm{~mm})$ can be removed and a long, smooth-shafted carrier $(7 \mathrm{~mm})$, reimplanted without any loss of spiral ganglion cells in only one out of the four cats' ears. With the explantation and reimplantation of the long smooth shaft carrier there was no loss of ganglion cells in two out of four ears. Overall, however, there was additional trauma associated with reinsertion.

At the University of Melbourne we have also carried out an explantation and reimplantation study on cats. The study was performed on 10 cats using the Cochlear smooth, tapered, free-fitting multiple-electrode array. On one side the electrode was inserted as a control and on the other it was implanted and left for 3 mo before being explanted and another reimplanted. The cochlea was examined histologically and the ganglion cells counted. Preliminary results have shown that the smooth-shafted Cochlear electrode can be explanted and another reimplanted with minimal loss of spiral ganglion cells. Losses were more likely to occur, how- ever, if repeated attempts were made to reimplant the electrode. This occurred when granulation tissue was present at the round window, as this obscured the opening.

Our experience with reimplanting the Cochlear device in patients has shown the procedure can be made difficult if the tissue around the round window obscures the electrode entry point. In patients this was not due to granulation tissue, as found in cats, but simply due to the retraction of tissue outside the round window. The problem can be avoided by incising the tissue around the electrode entry point and making sure there is a good view inside the sheath leading into the scala tympani.

Furthermore, we have also found that when the Cochlear electrode was replaced, there was no decrement in clinical performance (Clark et al, 1987). Removing a single-channel implant and replacing it with a multiple-channel device also had no adverse functional effect (Brimacombe, Beiter, Barker, Mikami, \& Staller, 1988; Lindeman, Mangham, \& Kup, 1987).

Further studies are being undertaken on explantation and reimplantation in the monkey as part of the NIH contract "Studies on Pediatric Auditory Prostheses Implants" (No. 1-NS-7-2342).

\section{Extracochlear Stimulation}

Studies are being carried out to see if extracochlear stimulation could be undertaken in children under 2 before their receiving an intracochlear multiple-electrode system from $2 \mathrm{yr}$ of age and above.

This is necessary if our safety studies show that there is any risk to residual hearing present. This is not always easy to diagnose in this age group. We have, however, developed a technique for averaging auditory evoked responses to steady state stimuli that can assess thresholds for low as well as high frequencies in this population (Rickards \& Clark, 1984). This has not hitherto been so readily achievable with standard evoked response techniques.

If extracochlear stimulation is required before $2 \mathrm{yr}$ of age, then physiological studies being undertaken on cats should provide data to show to what extent multiplechannel stimulation might be possible. They are also showing that extracochlear stimulation can cause facial nerve responses unless special measures are taken to minimize the spread of current outside the cochlea.

We are also carrying out safety studies on cats to see whether the electrical stimulus parameters to be used with either multiple- or single-channel extracochlear stimulation damage auditory neurons or residual hair cells.

\section{REFERENCES}

Berkowitz RG, Franz BK-H, Shepherd RK, Clark GM, and Bloom DM. Pneumococcal middle ear infection and cochlear implantation. Ann Otol Rhinol Laryngol 1987;128(Suppl):55-56.

Bielamowicz SA, Coker NJ, Jenkins HA, and Igarashi M. Surgical dimensions of the facial recess in adults and children. Arch Otolaryngol Head Neck Surg 1988:1 14:534-537. 
Brennan WJ and Clark GM. An animal model of acute otitis media and the histopathological assessment of a cochlear implant in the ear. J Laryngol Otol 1985:99:851-856.

Brimacombe JA, Beiter AL, Barker MJ, Mikami KA, and Staller SJ. Comparative results of speech recognition testing with patients who have used both a single channel and multichannel cochlear implant system. In Frysse B and Cochard N. Eds. Cochlear Implants: Acquisitions and Controversies. Toulouse, France: Impasse La Caussade, 1988.

Clark GM and Shepherd RK. Cochlear implant round window sealing procedures in the cat. An investigation of autograft and heterograft materials. Acta Otolaryngol (Suppl) 1984;410:5-15.

Clark GM, Kranz HG, Minas H, and Nather JM. Histopathological findings in cochlear implants in cats. J Laryngol Otol 1975;89:495504.

Clark GM, Pyman BC, Webb RL. Franz BK-H, Redhead TJ, and Shepherd RK. Surgery for the safe insertion and reinsertion of the banded electrode array. Ann Otol Rhinol Laryngol (Suppl) 1987;96(Suppl 128):10-12.

Clark GM, Franz BK-H, Pyman BC, Webb RL, Balkany T, Cohen NL, and Gantz BJ. Nucleus 22 channel cochlear implant system surgical procedure manual, Englewood, CO: Cochlear Corporation, 1987.

Cohen NL, Hoffman RA, and Stroschein M. Medical or surgical complications related to the nucleus multichannel cochlear implant. Ann Otol Rhinol Laryngol 1988;97(Suppl 135):8-13.

Cranswick NE, Franz BK-H, Clark GM, Shepherd RK, and Bloom DM. Middle ear infection postimplantation: Response of the round window membrane to streptococcus pyogenes. Ann Otol Rhinol Laryngol (Suppl) 1987;128:53-54.

Franz BK-H, Clark GM, and Bloom DM. Permeability of the implanted round window membrane in the cat. An investigation using horseradish peroxidase. Acta Otolaryngol 1984; (Suppl)410:17-23.

Franz BK-H, Clark GM, and Bloom DM. Cochlear implants and otitis media: A comparison of cochlear implant insertion techniques, and the effects of otitis media induced with group A streptococci. Ann Otol Rhinol Laryngol 1987;96:174-177.

Franz BK-H, Shepherd RK, and Clark GM. Animal models: Otitis media. Comparative Pathology Bulletin, Armed Forces Institute of Pathology 1991;23:2.
House WF, Luxford WM, and Courtney B. Otitis media in children following the cochlear implant. Ear Hear 1985;6:245-265.

Jackler RK, Leake PA, and McKerrow WS. Cochlear implant revision: The effects of reimplantation on the cochlea. Proc Am Otol Soc in San Francisco. 1989.

Lindeman RC, Mangham CA, and Kup MA. Single-channel and multichannel performance for reimplanted cochlear prosthesis patient. Ann Otol Rhinol Laryngol 1987;96(Suppl 128):150-151.

Rickards FW and Clark GM. Steady state evoked potentials to amplitude-modulated tones. In Nodar $\mathrm{RH}$ and Barber $\mathrm{C}$, Eds. Evoked Potentials II: The Second International Evoked Potentials Symposium, Boston: Butterworths, 1984;163-168.

Shepherd RK. Clark GM, and Black RC. Chronic electrical stimulation of the auditory nerve in cats. Acta Otolaryngol 1983:(suppl)399:19-31.

Shepherd RK, Xu SA, Jonathan DA, Matsushima J, Ni D, Xu J, Franz BK-H, Clark GM, Purser S, Millard RE, Tong YC, Redhead TJ, Kuzma JA. and Patrick JF. Studies on pediatric auditory prosthesis implants. Tenth Quarterly Progress Report, August 1October 31, 1984

Webb RL. Pyman BC. Franz BK-H. and Clark GM. The surgery of cochlear implantation. In Clark GM, Tong YC, Patrick JF, Eds. London: Churchill Livingstone, 1990.

Webb RL, Lehnhardt E, Clark GM, Laszig R, Pyman BD, and Franz BK-H. (in press). Surgical complications with the Cochlear multiple-channel intra-cochlear implant: Experience at Hannover and Melbourne. Ann Otol Rhinol Laryngol 1991;100:131-136.

Acknowledgments: We would like to thank our colleagues Drs. B. KH. Franz, R. Hoffman, D. Jonathan, J. Matsushima, D. Ni, B. C. Pyman, R. L. Webb, J. Xu, and S. A. Xu for their involvement and contributions to this work. We acknowledge with gratitude the support of the National Institutes of Health for the safety studies. Cochlear Corporation has assisted in the preparation of the manuscript, including the figures, which were drawn by Mr. Ed Zilberts.

Address reprint requests to Graeme M. Clark, FRACS, Department of Otolaryngology, Royal Victoria Eye and Ear Hospital, 32 Gisborne Street, E. Melbourne, Victoria, Australia 3000. 


\section{University Library}

\section{- M M N E R VA A gateway to Melbourne's research publications}

Minerva Access is the Institutional Repository of The University of Melbourne

Author/s:

Clark, Graeme M.;Cohen, Noel L.;Shepherd, Robert K.

Title:

Surgical and safety considerations of multi-channel cochlear implants in children

Date:

1991

Citation:

Clark, G. M., Cohen, N. L., \& Shepherd, R. K. (1991). Surgical and safety considerations of multi-channel cochlear implants in children. Ear and Hearing, 12(suppl.4), 15-24.

Persistent Link:

http://hdl.handle.net/11343/27297 